Conclusions: Our data from a large CTD cohort suggest that rare Abs associate with distinct features in particular ILD and inflammatory myositis. A majority of these patients fulfil the criteria for overlap syndrome and SSc.

Disclosure of Interest: None declared

DOI: 10.1136/annrheumdis-2018-eular.5842

\section{AB0747 INTERSTITIAL LUNG DISEASE IS INDEPENDENTLY ASSOCIATED WITH INCREASED FAECAL CALPROTECTIN LEVELS IN SYSTEMIC SCLEROSIS}

C. Caimmi ${ }^{1}$, E. Bertoldo ${ }^{1}$, A. Venturini ${ }^{1}$, P. Caramaschi ${ }^{1}$, L. Frulloni ${ }^{2}$,

R. Ciccocioppo ${ }^{2}$, S. Brunelli ${ }^{2}$, L. Idolazzi ${ }^{1}$, D. Gatti ${ }^{1}$, O. Viapiana ${ }^{1}$, M. Rossini ${ }^{1}$.

${ }^{1}$ Rheumatology Unit, ${ }^{2}$ Gastroenterology Unit, University of Verona, Verona, Italy

Background: Interstitial lung disease (ILD) is one of the leading cause of death in systemic sclerosis (SSc).

Objectives: The aim of this paper was to evaluate the relationship between faecal calprotectin (FC) and ILD.

Methods: 129 outpatients with SSc were enrolled. Data about disease characteristics, in particular lung involvement, were collected and FC was measured.

Results: Eighty-seven patients $(67.4 \%$ ) had a limited subset with a mean disease duration of 13.3 (7.1) years. Anti-Scl70 antibodies were found in 35 (27.1\%) patients. GI tract involvement was severe/end stage in 3 cases (2.4\%). ILD affected 35 patients (27.1\%). Median levels of FC were $80 \mathrm{ug} / \mathrm{g}(157 \mathrm{ug} / \mathrm{g})$. FC was found to be higher in patients with a moderate/severe/end stage score for gastrointestinal tract $(p=0.046)$ and on steroids $(p=0.015)$. In addition, it positively correlated with age $(p<0.001)$

Other than well-known risk factors such as higher mRSS or diffuse subset, patients with ILD had higher values of FC $(p<0.001)$. In multivariate analysis correcting also for factors affecting $\mathrm{FC}$ levels (i.e. disease duration, mRSS, Valentini activity score, total Medsger severity score, proton pump inhibitor, anti-Scl-70 antibody, diverticulosis, limited cutaneous subset, faecal calprotectin levels, steroid treatment), diffuse disease subset $(p=0.001)$, higher mRSS $(0.04)$, longer disease duration (0.046), higher severity scores $(0.026)$, higher FC levels $(p=0.003)$ and steroid treatment $(0.014)$ were associated with increased risk of ILD, while diverticulosis was protective. In addition, we ran a second multivariate analysis considering the 110 cases with FC level $<275 \mu \mathrm{g} / \mathrm{g}$, in order to correct for a possible small intestine bacterial overgrowth. Increased FC levels $(p=0.019)$, steroid treatment $(p=0.03)$, higher severity scores $(p=0.016)$ and diffuse disease subset $(p=0.002)$ were confirmed to be associated with ILD.

Conclusions: in this paper we have found a possible link between gut inflammation and ILD. Many hypothesis may be done but it is intriguing that these data further support what previously found by other authors (Andreasson et al. 2016), that is a correlation between gut inflammation and dysbiosis and non-gastrointestinal disease manifestation. Our study may support the hypothesis of a role of gut dysbiosis in triggering a pathologic immune response leading to ILD. It may also be that increased FC simply reflects a more severe disease but this still doesn't explain why only ILD was found to be linked with FC. Is it because lung is a filter of molecule (i.e. antigens, cytokines, metabolites, etc.) produced in the gut? Further studies with longitudinal evaluation are warranted.

Disclosure of Interest: None declared

DOI: 10.1136/annrheumdis-2018-eular.2533

\section{AB0748 POLIAUTOIMMUNITY IN SCLERODERMA: DATA FROM DE SPANISH SCLERODERMA REGISTRY}

D. Sanchez-Cano ${ }^{1}$, M. Trigo-Rodríguez ${ }^{1}$, A. Guillén del Castillo ${ }^{2}$, on behalf of RESCLE, R. Ríos-FernándeZ ${ }^{1}$, C. Tolosa-Vilella ${ }^{3}$, on behalf of RESCLE, M. RubioRivas $^{4}$, on behalf of RESCLE, M. Freire ${ }^{5}$, on behalf of RESCLE, J. A. TodolíParra $^{6}$, on behalf of RESCLE, M. Rodríguez-Carballeira ${ }^{7}$, A. Marín-Ballvée ${ }^{8}$, on behalf of RESCLE, V. Fonollosa-Plá ${ }^{9}$, on behalf of RESCLE, C.P. Simeón-Aznar ${ }^{10}$ on behalf of RESCLE. ' Unidad de Enfermedades Autoinmunes Sistémicas, Hospital Campus de la Salud, Granada; ${ }^{2}$ Unidad de Enfermedades Autoinmunes Sistémicas, Hospital Vall D'Hebron, Barcelona; ${ }^{3}$ Servicio de Medicina Interna, Corporación Sanitaria Universitaria Parc Taulí, Sabadell, Barcelona; ${ }^{4}$ Unidad de Enfermedades Autoinmunes Sistémicas, Hospital Universitario de Bellvitge., L'Hospitalet de Llobregat, Barcelona; ${ }^{5}$ Unidad de Enfermedades Autoinmunes Sistémicas, Complejo Hospitalario Universitario de Vigo, Vigo; ${ }^{6}$ Servicio de Medicina Interna, Hospital Universitario y Politécnico La Fe, Valencia; ${ }^{7}$ Servicio de Medicina Interna, Hospital Universitario Mútua Terrassa, Terrassa; ${ }^{8}$ UNIDAD de Enfermedades Autoinmunes Sistémicas, Hospital Clínico Universitario Lozano Blesa., Zaragoza; ${ }^{9}$ UNIDAD de Enfermedades Autoinmunes, Hospital Universitario Vall d'Hebron; ${ }^{10}$ UNIDAD de Enfermedades Autoinmunes, Hospital Universitario Vall d'Hebron, Barcelona, Spain

Background: Systemic sclerosis (SSc) is a disorder with a well-known autoimmune base. There is evidence suggesting a common background with other connective tissue diseases, thus predisposing to the development of other autoimmne disorders in these patients, that is, poliautoimmunity (PAI).

Objectives: To assess PAI in a cohort of SSc patients.

Methods: A nationwide, cross-sectional study was performed including the 1928 patients enrolled in the Spanish SSc Registry (RESCLE). Ethics Committee approval was obtained by all participating centres.

Results: Prevalence of PAI was $45 \%$, with $32 \%$ having more than one association. Most of these patients were women $(93 \%, p<0.001)$, with older age at diagnosis $(53,7 \pm 14,7$ years, $p=0.027)$. Regarding subtypes, $P A I$ was singnificantly more frequent in limited cutaneous SSc $(48 \%, p=0.004)$ and pre-Ssc $(47 \%, p<0.001)$. Sjögren's syndrome was by far the most common association ( $55 \%$ ), followed by global autoimmune thyroid disorders $(31 \%)$, autoimmune liver disorders $(17 \%)$ and inflammatory myopathies (12\%). Clinical features are shown on table 1.

Abstract AB0746 - Table 1. Diagnosis and clinical features in patients positive for rare antibodies

\begin{tabular}{|c|c|c|c|c|c|c|c|c|c|c|c|}
\hline \multirow[b]{2}{*}{$\begin{array}{l}\text { Antibody(n, } \\
\%)\end{array}$} & \multicolumn{6}{|c|}{ Diagnosis } & \multicolumn{5}{|c|}{ Clinical features } \\
\hline & SSc & SLE & ss & IM & Overlap & UCTD & ILD & PAH & IM & Arthritis & Renal \\
\hline Jo1(72) & 0 & 0 & 0 & $\begin{array}{c}51 \\
(70.8)\end{array}$ & $21(29.2)$ & 0 & $\begin{array}{c}51 \\
(70.8)\end{array}$ & $\begin{array}{c}11 \\
(15.3)\end{array}$ & $72(100)$ & $21(29.2)$ & 0 \\
\hline PCNA ${ }^{7}$ & $1(14.3)$ & $6(85.7)$ & 0 & 0 & 0 & 0 & 0 & $1(14.3)$ & 0 & $4(57.1)$ & $3(42.9)$ \\
\hline$X R\left(^{22}\right.$ & $9(40.9)$ & $6(27.3)$ & 0 & 0 & $7(31.8)$ & 0 & $9(40.9)$ & $7(31.8)$ & $3(13.6)$ & $6(27.3)$ & $1(4.5)$ \\
\hline PL-4(11) & 0 & $11(100)$ & 0 & 0 & 0 & 0 & 0 & 0 & 0 & 0 & $5(45.5)$ \\
\hline PL-7(17) & $2(11.8)$ & 0 & 0 & $9(52.9)$ & $6(35.3)$ & 0 & $\begin{array}{c}14 \\
(82.4)\end{array}$ & 0 & $\begin{array}{c}15 \\
(88.2)\end{array}$ & $5(29.4)$ & 0 \\
\hline PL-12( ${ }^{12}$ & $2(16.7)$ & $2(16.7)$ & $1(8.3)$ & $5(41.7)$ & $2(16.6)$ & 0 & $9(75.0)$ & 0 & $6(50.0)$ & 4 (33.3) & $1(8.3)$ \\
\hline $\operatorname{SRP}\left(^{9}\right.$ & 0 & 0 & 0 & $5(55.6)$ & $4(44.4)$ & 0 & $6(66.7)$ & $2(22.2)$ & $\begin{array}{c}9 \\
(100.0)\end{array}$ & $1(11.1)$ & 0 \\
\hline $\mathrm{Ku}\left({ }^{47}\right.$ & $\begin{array}{c}14 \\
(29.8)\end{array}$ & $5(10.6)$ & 0 & $2(4.3)$ & $21(44.7)$ & $\begin{array}{c}5 \\
(10.6)\end{array}$ & $\begin{array}{c}21 \\
(44.7)\end{array}$ & $2(4.3)$ & $8(17.0)$ & $16(34.0)$ & $4(8.5)$ \\
\hline Mi-2(7) & 0 & 0 & 0 & $6(85.7)$ & 1 (14.3) & 0 & $4(57.1)$ & 0 & $1(14.7)$ & 0 & 0 \\
\hline $\mathrm{EJ}\left(^{2}\right.$ & $1(50.0)$ & 0 & 0 & 0 & $1(50.0)$ & 0 & $1(50.0)$ & 0 & 0 & 0 & 0 \\
\hline SL(94) & $\begin{array}{c}33 \\
(35.1)\end{array}$ & $\begin{array}{c}34 \\
(36.1)\end{array}$ & $\begin{array}{c}10 \\
(10.6)\end{array}$ & $1(1.1)$ & $10(10.7)$ & $6(6.4)$ & $\begin{array}{c}16 \\
(17.0)\end{array}$ & $9(9.6)$ & $\begin{array}{c}12 \\
(12.7)\end{array}$ & $36(38.3)$ & $\begin{array}{c}14 \\
(14.9)\end{array}$ \\
\hline $\mathrm{Pm} / \mathrm{Scl}(182)$ & $\begin{array}{c}70 \\
(38.7)\end{array}$ & $2(1.1)$ & $1(0.6)$ & $6(3.3)$ & $99(54.7)$ & $3(1.7)$ & $\begin{array}{c}75 \\
(41.4)\end{array}$ & $11(6.1)$ & $\begin{array}{c}94 \\
(51.9)\end{array}$ & 35 (19.3) & $10(5.5)$ \\
\hline rRNP( ${ }^{5}$ & 0 & $5(100)$ & 0 & 0 & 0 & 0 & $1(20.0)$ & 0 & 0 & $2(40.0)$ & $3(60.0)$ \\
\hline $\mathrm{Th} / \mathrm{To}{ }^{40}$ & $\begin{array}{c}34 \\
(85.0)\end{array}$ & 0 & 0 & $1(2.5)$ & $4(10.0)$ & $1(2.5)$ & $\begin{array}{c}16 \\
(40.0)\end{array}$ & $\begin{array}{c}10 \\
(25.0)\end{array}$ & $5(25.0)$ & $2(5.0)$ & $1(2.5)$ \\
\hline NuMA-1(2) & $\begin{array}{c}2 \\
(100.0)\end{array}$ & 0 & 0 & 0 & 0 & 0 & 0 & 0 & 0 & $1(50.0)$ & 0 \\
\hline $0 \mathrm{~J}\left({ }^{1}\right.$ & 0 & 0 & 0 & $\begin{array}{c}1 \\
(100.0)\end{array}$ & 0 & 0 & $\begin{array}{c}1 \\
(100.0)\end{array}$ & 0 & $\begin{array}{c}1 \\
(100.0)\end{array}$ & $1(100.0)$ & 0 \\
\hline$h n R N P\left(^{3}\right.$ & $0(0.0)$ & $2(66.7)$ & $0(0.0)$ & $0(0.0)$ & $0(0.0)$ & $\begin{array}{c}1 \\
(33.3) \\
\end{array}$ & $0(0.0)$ & $0(0.0)$ & $0(0.0)$ & $3(100.0)$ & $0(0.0)$ \\
\hline
\end{tabular}


Abstract AB0748 - Table 1

\begin{tabular}{lcccc}
\hline & TOTAL & $\begin{array}{c}\text { ISOLATED } \\
\text { SSC }\end{array}$ & PAI & $p$ \\
\hline Raynaud's Phenomenon & 1826 & $1005(55 \%)$ & $821(45 \%)$ & 1.000 \\
Digital ulcers & 745 & $408(55 \%)$ & $337(45 \%)$ & 0.888 \\
Calcinosis & 322 & $142(44 \%)$ & $180(56 \%)$ & $<0.001$ \\
Arthritis & 270 & $128(47 \%)$ & $142(53 \%)$ & 0.064 \\
Myositis & 172 & $37(22 \%)$ & $135(78 \%)$ & $<0.001$ \\
Gastrointestinal involvement & 1222 & $632(52 \%)$ & $590(48 \%)$ & $<0.001$ \\
ILD & 795 & $399(50,2 \%)$ & 396 & $<0.001$ \\
& 148 & $66(45 \%)$ & $82(55 \%)$ & 0.438 \\
PH confirmed by right heart & & & $(49.8 \%)$ & \\
catheterisation & 409 & $196(48 \%)$ & $213(52 \%)$ & 0.001 \\
Heart involvement & 43 & $27(63 \%)$ & $16(37 \%)$ & 0.353 \\
Scleroderma renal crisis & & &
\end{tabular}

We found no significant differences concerning capillaroscopy patterns, or causes of death, neither SSc-related nor non-Ssc-related.

Finally, a multivariate analysis with logistic regression was performed to evaluate the risk factors for $\mathrm{PAI}$, which are shown on the table 2.

Abstract AB0748 - Table 2

\begin{tabular}{lcc}
\hline Variables & $\begin{array}{c}\text { Multivariate analysis } \\
\text { OR }(95 \% \text { I.C.) }\end{array}$ & p value \\
\hline Gender & $2,72^{1,87-3,98}$ & $<0001$ \\
Age at dianosis & $1,01^{1,00-1,02}$ & 0012 \\
Calcinosis & $1,63^{1,23-2,16}$ & $<0001$ \\
ILD & $1,37^{1,08-1,73}$ & $<0001$ \\
Gastrointestinal involvement & $1,32^{1,05-1,66}$ & 0019 \\
Centromere Ab & $1,41^{1,12-1,77}$ & $<0001$ \\
Ro Ab & $1,61^{1,18-2,18}$ & $<0001$ \\
\hline
\end{tabular}

Conclusions: PAI in SSc is a frequent condition that special attention in these patients. We found a rather higher prevalence compared with those published in the literature, even though the distribution of those associated disorders was similar. In our cohort, there were no remarkable differences between both groups concerning clinical manifestations (although not always statistically significant). Finally, certain circumstances should make us aware of a possible associated condition to SSc.

\section{REFERENCE:}

[1] Elhai M, Avouac J, Kahan A, Allanore Y. Systemic sclerosis at the crossroad of polyautoimmunity. Autoimmun Rev. 2013;12:1052-7.

Disclosure of Interest: None declared

DOI: 10.1136/annrheumdis-2018-eular.3545

\section{AB0749 DON'T FORGET THE CAREGIVERS OF PATIENTS WITH SYSTEMIC SCLEROSIS}

M. Boonstra ${ }^{1}$, D.F. Stoop ${ }^{1}$, T.W. Huizinga ${ }^{1}$, T.P. Vliet Vlieland ${ }^{2}$, J.K. de VriesBouwstra ${ }^{1} .{ }^{1}$ department of Rheumatology; ${ }^{2}$ department of Orthopedics, Leiden University Medical Center, Leiden, Netherlands

Background: Systemic sclerosis (SSc) is a disease with considerable physical and psychosocial impact. Previous studies among partners of patients with other chronic diseases, such as Parkinson's and stroke, showed that $6 \%-25 \%$ of caregivers experience high levels of stress related to caregiving. To our knowledge, the burden experienced by caregivers of patients with SSc has not been determined so far.

Objectives: To evaluate perceived strain, quality of life and health care needs among SSc caregivers.

Methods: During a patient information meeting, companions of SSc patients were invited to complete 3 questionnaires: 1 . The Caregiver Strain Index questionnaire (CSI), in which a score $>7$ indicates high care burden, 2. Short Form-36 (SF-36): a measure of self-reported Quality of Life (QoL) and 3. a self-designed questionnaire on the needs and preferences for caregiving support. Caregivers with and without high care burden were compared regarding their general characteristics and Qol.

Results: Thirty-six SSc caregiver filled out questionnaires ( $n=31$ completed the CSI questionnaire). Respondents were mostly men (64\%), on average 62 years old (SD 14), 35\% ( $n=11)$ had a paid job, and $50 \%(n=18)$ suffered from chronic disease. The majority was in a spousal relationship $(75 \%)$ with the SSc patient and $56 \%$ of patients had been diagnosed with SSc more than 5 years ago. Nineteen percent of patients $(n=7)$ needed daily personal caregiving and $25 \%(n=9)$ was transport-dependent. Median CSI was 2 (range 0 to 5), and 6/31 (19\%) perceived high care burden(CSI $\geq 7)$. Caregivers with high care burden were significantly more often involved in daily personal caregiving of the patients (3/6 vs. 2/25) Although not statistically significant, all caregivers perceiving a high burden were spouses, while the remaining caregivers had varying relationships with SSC patients. SF-36 summary scale scores were similar in both groups (table 1). Regarding needs and preferences of caregivers, $15 \%(n=5)$ reported a need for additional individual information, and $21 \%(n=7)$ a need for contact with fellow caregivers of patients, preferably during information meetings.

Abstract AB0749 - Table 1. Characteristics of caregivers of SSc patients with and without high care burden (CSI $\geq 7)$.

\begin{tabular}{|c|c|c|c|c|}
\hline & Total $(n=36)$ & $\begin{array}{l}\text { CSI }<7 \\
(n=25)\end{array}$ & $\begin{array}{c}\mathrm{CSI} \geq 7 \\
(\mathrm{n}=6)\end{array}$ & $p$-value \\
\hline CSI, median (IQR) & $\begin{array}{c}2.0(0.0- \\
5.0)^{* *}\end{array}$ & $\begin{array}{c}2.0(0.0- \\
4.0)\end{array}$ & $\begin{array}{l}8.0(7.0- \\
8.0)\end{array}$ & n.a. \\
\hline Gender, $\mathrm{n}$ (\% female) & $13(36)$ & $10(40)$ & $1(17)$ & $0.383^{1}$ \\
\hline Age (years, median (IQR) & $\begin{array}{l}65.5(53.8- \\
72.0)\end{array}$ & $\begin{array}{l}66.0(51.0- \\
73.0)\end{array}$ & $\begin{array}{l}63.5(56.8- \\
\quad 66.0)\end{array}$ & $0.448^{2}$ \\
\hline \multicolumn{5}{|l|}{ Relationship (\%) } \\
\hline Partner & $27(75)$ & $18(72)$ & $6(100)$ & $0.293^{1}$ \\
\hline Father/mother & $2(6)$ & $2(8)$ & $0(0)$ & \\
\hline Friend & $2(6)$ & $1(4)$ & $0(0)$ & \\
\hline Son/daughter & $4(11)$ & $4(16)$ & $0(0)$ & \\
\hline $\begin{array}{l}\text { Involved in daily personal caregiving } \\
\text { patient SSc (\%) }\end{array}$ & $7(19)^{*}$ & $2(8)$ & $3(50)$ & $0.038^{1}$ \\
\hline $\begin{array}{l}\text { Transport dependency patient SSc (\%) } \\
\text { SF - } 36 \text { (mean } \pm \text { SD) }\end{array}$ & $9(25)^{*}$ & $5(20)$ & $2(33)$ & $0.596^{1}$ \\
\hline Physical component score & $50.9 \pm 7.2^{\star \star *}$ & $\begin{aligned} & 51.2 \\
\pm & 7.0^{\star \star \star \star *}\end{aligned}$ & $53.6 \pm 3.4$ & \\
\hline Mental component score & $43.7 \pm 6.8^{\star \star *}$ & $\begin{array}{c}43.4 \\
\pm 7.8^{\star \star \star \star}\end{array}$ & $42.9 \pm 3.8$ & \\
\hline
\end{tabular}

${ }^{1}$ Fisher's exact ${ }^{2}$ Mann-Withney $U$ *n=35, ${ }^{* \star} n=31,{ }^{* \star *} n=28,{ }^{* \star \star *} n=19$

Conclusions: Within a small group of SSc caregivers, $19 \%$ experienced high care burden. In particular caregivers involved in personal caregiving seem to be at risk for increased strain related to caregiving. The results of the current study can direct clinical practice aiming at support of the caregivers.

Disclosure of Interest: None declared

DOI: 10.1136/annrheumdis-2018-eular.6404

\section{AB0750 RHEUMATIC DISEASES WITH LUNG INVOLVMENT AND PSYCHOLOGICAL STATUS}

D. Abdulganieva, N. Shamsutdinova, G. Nurullina, E. Kirillova, E. Makaricheva, A. Krasnov, A. Surikov. Kazan State Medical University, Kazan, Russian Federation

Objectives: assess the impact of psychological status indicators on lung function in patients with rheumatic diseases with lung lesions

Methods: A study of 30 patients with diagnoses of systemic scleroderma (SSD) 14 patients, systemic vasculitis $(C B)-10$, rheumatoid arthritis (RA) -6 patients. The average age of the patients was $56.55 \pm 10.59$ (from 22 to 77 years). All patients had high activity of the underlying disease and received pathogenetic therapy in the form of pulse therapy for HA -19 patients, high doses of HA (1 mg/ $\mathrm{kg}$ ) per os - 11 patients; were hospitalised in connexion with the first detected lung lesions or signs of progression of the existing lung injury (increased dyspnea, reduced exercise tolerance). Patients are consulted by a cardiologist to exclude the cardiac genesis of symptoms.

All patients underwent a standard clinical examination, in addition they performed: high-resolution RCT of lung (64-slice CT system Philips Diamond Select Brilliance), a 6 min walk test.

Evaluation of lung function was carried out using spirometry, bodipletizmography, diffusion "single breath".

The following scales were used to assess the psychological status: State-Trait Anxiety Inventory (STAlpersonal and situational anxiety assessment, symptomatic questionnaire SCL-90-R (English Simptom Check List-90-Revised), anxiety and depression, the Toronto Alexitimic Scale (TAS)

Results: All patients according to RKT data had manifestations of IZL in the form of nonspecific interstitial pneumonia. Among the patients examined, the group with DV 1 st. was 11 patients, DN 2 tbsp. -14 patients, DN 3 tbsp. -5 patients.A high level of situational anxiety was present in 11 patients $(36.7 \%)$, personal - in 13 patients $(43.3 \%)$. At the same time, the DLCO relationship to the alveolar volume was identified with the level of personal anxiety $(r=-0.526, p<0.05)$ and situational $(r=-0.423, p<0.05)$. In addition, the DV index has an average correlation with the level of anxiety $(r=0.513, p<0.05)$. The symptomatic questionnaire revealed a significant degree of somatization in patients with IBD - in 14 patients 
$(46.7 \%)$, which is the somatic equivalent of depression and anxiety. TAS data indicate the presence of apparent alexithymia in 10 patients (33.3\%), the "risk group" for alexithymia is $26.7 \%$.

In addition, saturation after a 6 min walk was correlated with alexithymia $(r=-0.526, p<0.05)$

Conclusions: The psychological status of patients with rheumatic diseases with lung involvement in the form of nonspecific interstitial pneumonia is characterised by depression, anxiety, alexithymia.

Disclosure of Interest: None declared

DOI: 10.1136/annrheumdis-2018-eular.7560

\section{AB0751 THE EPSTEIN-BARR VIRUS INFECTION IN SYSTEMIC SCLEROSIS}

G. Efthymiou1, C. Liaskos ${ }^{1}$, E. Marou ${ }^{1}$, E. Dardiotis ${ }^{2}$, V. Tsimourtou ${ }^{2}$, T. Scheper ${ }^{3}$ W. Meyer ${ }^{3}$, D.P. Bogdanos ${ }^{1}$, G. Hadjigeorgiou ${ }^{2}$, L.I. Sakkas ${ }^{1} .{ }^{1}$ Rheumatology and Clinical Immunology, ${ }^{2}$ Neurology, Faculty of Medicine, School of Health Sciences, University of Thessaly, Larissa, Greece; ${ }^{3}$ Institute of Immunology, EUROIMMUN, Lübeck, Germany

Background: Epstein-Barr virus (EBV) infection has been considered trigger of various autoimmune diseases, including systemic sclerosis (SSc), mainly due to studies investigating cross-reactive responses amongst EBV and disease-specific antigens. Meticulous assessment of antibody reactivities to the most immunodominant EBV antigens in SSc has not been performed.

Objectives: To assess ab reactivity against EBV viral capsid antigens (VCA), early antigens (EA) and EBNA-1 in SSc, and investigate their clinical relevance. Methods: Sera from 59 SSc patients, including 31 diffuse SSc (dcSSc) and 28 limited SSc (ICSSc), 43 matched multiple sclerosis (MS) as controls and 32 matched healthy controls $(\mathrm{HC})$ were tested for IgG anti-EBV VCA, EA and EBNA1 abs by immunoblotting, using EBV whole SDS extract as antigen substrate. Results: Percentages of EA and EBNA-1 reactivities were significantly higher in SSc patients compared to HC (EA: $33.9 \%$ vs $3.1 \%, p=0.001$; EBNA-1: $89.8 \%$ vs $68.8 \%, p=0.012)$, but were comparable between SSc and MS. These differences remained when SSc was divided in dcSSc and IcSSc (EA: $32.3 \%$ in dcSSc and $35.7 \%$ in lcSSc, $p_{\text {dcSSc v } \mathrm{HC}}=0.002, p_{\text {lcSSc v } \mathrm{HC}}=0.001$; EBNA: $92.9 \%$ in lcSSc, $p$ IcSSc vs $\mathrm{HC}=0.020)$. VCA positivity was comparable between $\mathrm{SSc}$ or its two subgroups and MS or HCs. Also, triple positivity for all three antigen categories was observed more frequently in SSc, dcSSc and IcSSc compared to HCs $(32.2 \%$ in SSc, $29 \%$ in dcSSc and $35.7 \%$ in IcSSc vs $3.1 \%$ in $\mathrm{HC}, \mathrm{p}=0.001, \mathrm{p}=0.004$ and $\mathrm{p}=0.001$, respectively). Anti- EA was present more frequently in SSc patients with calcinosis compared to those without $(75 \%$ vs $27.5 \%, \mathrm{p}=0.014)$ and tended to be more frequent in patients with pulmonary fibrosis compared to those without (47.8\% vs $25 \%, p=0.071)$

Conclusions: Antibodies against EBV appear to be more frequent in SSc than in healthy controls, and equally prevalent with MS, a disease known to be associated with anti-EBV antibody responses and a known risk factor for MS. Whether an EBV-specific response is also an initiating trigger of SSc remains to be investigated

Disclosure of Interest: G. Efthymiou: None declared, C. Liaskos: None declared, E. Marou: None declared, E. Dardiotis: None declared, V. Tsimourtou: None declared, T. Scheper Employee of: EUROIMMUN, W. Meyer Employee of: EUROIMMUN, D. Bogdanos: None declared, G. Hadjigeorgiou: None declared, L. Sakkas: None declared

DOI: 10.1136/annrheumdis-2018-eular.6599

\section{AB0752 CLINICAL FEATURES OF SYSTEMIC SCLEROSIS ASSOCIATED TO ANTI RNA POLYMERASE III ANTIBODIES IN VALLD'HEBRON HOSPITAL}

E.L. Callejas-Moraga ${ }^{1}$, A. Guillén-Del-Castillo ${ }^{2}$, A. Marín-Sánchez ${ }^{2}$, V. FonollosaPlá $^{2}$, E. Balada ${ }^{2}$, J. Martín ${ }^{3}$, C.P. Simeón-Aznar ${ }^{2} .{ }^{1}$ Internal Medicine, Parc Taulí Hospital; ${ }^{2}$ Internal Medicine, Hospital Vall d'Hebron, Barcelona; ${ }^{3}$ Instituto de Parasitología, Instituto de Parasitología y Biomedicina López Neira, Granada, Spain

Objectives: Systemic sclerosis (SSc) is an autoimmune disease whose clinical features are related closely with the specific autoantibody that is expressed. The main objective was to analyse the clinical characteristics of patients with positive anti-RNA polymerase III antibody (anti-RNAP III) and compare them with patients who were negative.

Methods: We analysed 221 patients with SSc who visited Valld'Hebron Hospital from 1980 to 2016. 26 patients who were positive were compared with 195 who were negative. Different epidemiological, clinical, capillaroscopic and immunological variables were analysed.

Data from the Vall d'Hebron Hospital cohort were collected from patients diag nosed with ES since 1980. 24 patients with positive anti-RNAP III antibodies were selected using the technique of immunoblot on paper or enzyme immunoassay and were compared with 151 who were negatives. Different epidemiological, clinical, capillaroscopic and immunological variables were analysed. Statistical analy sis was performed using SPSS 20.0. Statistical significance was considered $\mathrm{p}<0.05$

Results: 24 patients (13.7\%) showed anti-RNAP III reactivity. Female sex (151, $86.3 \%$ ) was the most frequent. There were no differences in the age at onset of the disease $(40.3 \pm 15.9)$ or in the age at diagnosis (46.6 \pm 15.7$)$. Diffuse cutaneous (Dc) subtype was more frequent in the anti-RNAP III group (70\% vs $16.6 \% \mathrm{p}<0.001)$. Patients with positive anti-RNAP III met the ACR/EULAR 2013 diagnostic criteria more frequently $(24,100 \%$ vs. $118,78.1 \% \mathrm{p}<0.01)$. Regarding the first manifestation, Raynaud's phenomenon was less frequent in the antiRNAP III group $(13,54.2 \%$ vs. $121,80.1 \%$ p $<0.01)$. Regarding to vascular features, there were no differences in digital ulcers $(15,62.5 \%$ vs. $66,43.7 \%$, $\mathrm{p}=0.08$ ), in the presence of Raynaud's phenomenon (24,100\% vs. $145,96.7 \%$ ) or telangiectasias (18, $75 \%$ vs. $102,67.5 \%)$. There were no differences with respect to the overall digestive involvement $(21,87.5$ vs. $124,82.1 \%)$ No differences were found in cardiac involvement in both groups (9, 37.5\% vs. $51,47 \%)$. Scleroderma renal crisis (SRC) was significantly more frequent in patients with anti-RNAP III (3, $12.5 \%$ vs. $3,1.9 \% \mathrm{p}=0.03)$. There were no differences in prevalence of cancer (4, $16.7 \%$ vs. $12,7.9 \% p=0.24)$. There were no differences in mortality $(2,8.3 \%$ vs $16,10.6 \%)$. The slow-type capillary pattern of Maricq was the most frequent in both groups $(20,83.3 \%$ vs. $132,87.4 \%)$. Regarding the expression of other auto antibodies, anti-Ro52 positivity was less frequent in patients with anti-RNAP III (2, $8.2 \%$ vs. $14,9.3 \% \mathrm{p}=0.03$ ).

Conclusions: Patients with ES who presented positivity for anti-RNA polymerase III antibodies had more frequent onset manifestations different from the Raynaud's phenomenon, more DcSSc subtype and higher frequency of SRC. Regarding positivity against other antibodies, they expressed less reactivity to anti-Ro 52 than patients without anti-RNA pol III antibodies.

Disclosure of Interest: None declared

DOI: 10.1136/annrheumdis-2018-eular.2433

\section{AB0753 COMPARATIVE STUDY OF SYSTEMIC SCLEROSIS WITH OTHER AUTOIMMUNE DISEASES FOR HEALTH- RELATED QUALITY OF LIFE}

E.H. Park ${ }^{1}$, V. Strand ${ }^{2}$, Y.J. Oh ${ }^{1}$, H. Kwon ${ }^{3}$, Y.W. Song ${ }^{1}$, E.B. Lee ${ }^{1}$. ${ }^{1}$ Seoul National University Hospital, Seoul, Korea, Republic of Ireland; ${ }^{2}$ Stanford University, California, USA; ${ }^{3}$ Gangnam Sungshim Hospital, Seoul, Korea, Republic of Ireland

Background: Systemic sclerosis (SSc) is a rare autoimmune disease characterised by fibrosis of the skin and multiple internal organ involvement. Previous stud ies reported a poorer health-related quality of life (HRQoL) in patients with SSc compared to the general population. However, very little is known about HRQoL of SSc as compared with other systemic autoimmune diseases, including rheumatoid arthritis (RA), systemic lupus erythematosus (SLE), and Sjogren's syndrome (SJS)

Objectives: To compare the HRQoL of patients with SSc and other systemic autoimmune disease and general population.

Methods: HRQoL was captured by the Korean short form-36 health survey version 2 (SF-36), short form-6D (SF-6D) and 3 level version of EuroQol five-dimensional (EQ-5D) descriptive system (EQ-5D-3L). Between March and July 2017 consecutive patients with SSc, and randomly chosen patients with RA, SLE and SJS were recruited from the outpatient rheumatology clinics of Seoul National University Hospital, and were asked to answer SF-36 and EQ-5D. Disease activity of RA was evaluated by Disease Activity Score 28-ESR (DAS 28-ESR), SLE by Systemic Lupus Erythematosus Disease Activity Index-2k (SLEDAI-2k), and SJS by EULAR Sjogren's syndrome disease activity index (ESSDAI). For patients with SSc, Korean version of Health Assessment Questionnaire Disability Index (HAQDI) and Systemic sclerosis HAQ-DI (SSc HAQ-DI) were also evaluated. Demo graphic, clinical, laboratory information were obtained through a medical chart review. Data on representative Korean healthy controls were obtained from a study of psychometric properties of the Korean SF-36 v2 for assessing the general population, which was performed on six hundred healthy Koreans.

Results: A total of 480 patients with SSc $(n=120), \operatorname{RA}(n=120)$, SLE $(n=120)$ and SJS ( $n=120)$ and 600 healthy controls were included. The demographic features of patients were similar to the known features of each rheumatic disease group. Patients with rheumatic diseases had significantly lower SF-36 scores $(p<0.001$ in all domains), SF-6D scores ( $p<0.001)$, EQ-5D-3L index scores and EQ-VAS $(p<0.001)$ than the healthy controls; adjustments for age and sex did not change those results. Patients with SSc showed significantly lower scores in the mental component summary scores compared with patients with RA (age and sex adjusted scores, $43.0 \pm 0.9$ vs $48.9 \pm 0.9 ; \mathrm{p}<0.001)$. Specifically, domain of menta health was lower in SSc patients than RA patients (age and sex-adjusted scores $61.3 \pm 1.8$ vs $71.7 \pm 1.8, \mathrm{p}<0.001)$. Among the physical domains scores, SSc 